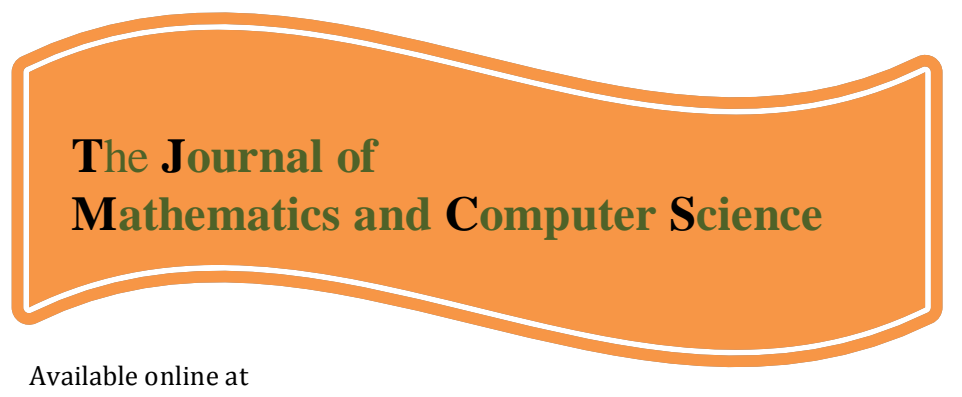

http://www.TIMCS.com

The Journal of Mathematics and Computer Science Vol.3 No.2 (2011) 145 - 155

\title{
A Note on Non Linear Optimal Inventory Policy Involving Instant Deterioration of Perishable Items with Price Discounts
}

\author{
M. Pattnaik \\ Dept. of Business Administration , Utkal University, \\ Bhubaneswar-751004, India \\ monalisha1977@gmail.com
}

Received: April 2011, Revised: June 2011

Online Publication: July 2011

\begin{abstract}
This paper derives a non linear optimal inventory policy involving instant deterioration of perishable items with allowing price discounts. This paper postulates that the inventory policy of perishable items very much resembles that of price discounts. Such a parallel policy suggests that improvements to production systems may be achievable by applying price discounts to increase demand rate of the perishable items. This paper shows how discounted approach reduces to perfect results, and how the post deteriorated discounted EOQ model is a generalization of optimization. The objective of this paper is to determine the optimal price discount, the cycle length and the replenishment quantity so that the net profit is maximized. The numerical analyses show that an appropriate discounted pricing policy can benefit the retailer and that discounted pricing policy is important, especially for deteriorating items. Furthermore the instant post deteriorated price discount crisp economic order quantity (CEOQ) model is shown to be superior in terms of profit maximization. The sensitivity analysis of parameters on the optimal solution is carried out.
\end{abstract}

Key Words: Discounted selling price, Instant deterioration, Constant demand, Inventory 


\section{Introduction}

In the development of an EOQ system, the case of price discount and deterioration of the items are usually omitted. But in the real world, they exist and are quite flexible in nature. On the other hand, in order to motivate customers to order more quantities, usually the price discounts are allowed to obtain the maximum payoff. In many inventory systems, the deterioration of goods is a realistic phenomenon. In addition, the product perishability is an important aspect of inventory control. Deterioration in general, may be considered as the result of various effects on stock, some of which are damage, decreasing usefulness and many more. While kept in store fruits, vegetables, food stuffs, bakery items etc. suffer from depletion by decent spoilage. Lot of articles are available in inventory literature considering deterioration. Interested readers may consult the survey paper of [3], [5],[6], [8], [12], [13], [14] and [21] classified perishability and deteriorating inventory models into two major categories, namely decay models and finite lifetime models. Products which deteriorate from the very beginning and the products which start to deteriorate after a certain time. Lot of articles are available in inventory literature considering deterioration. As a pioneer in deterioration model, [9] identified different criteria for this problem including fuzzy and permissible delay in payment. If this product starts to deteriorate as soon as it is received in the stock, then there is no option to provide pre-deterioration discount. Only it is possible to give post deterioration discount on selling price. The objective is to find optimal values of the policy variables when the criterion is to optimize the expected total payoff over a finite horizon.

In last two decades the variability of inventory level dependent demand rate on the analysis of inventory system was described by researchers like [4], [15] and [18]. They described the demand rate as the power function of on hand inventory. There is a vast literature on stock development inventory and its outline can be found in the review article by [11] where he unified two types of inventory level dependent demand by considering a periodic review model. Researchers such as [4], [13], [14], [18], [19], [22] and [16] discussed the EOQ model assuming time value of money, demand rate, deterioration rate, shortages and so on a constant or probabilistic number or an exponential function. [5] and [10] suggested EOQ models with stock dependent demand for perishable items. This paper considers demand as a constant function for instant deterioration model.

Every organisation dealing with inventory faces a numbers of fundamental problems. Pricing decision is one of them. In the development of an EOQ system, I usually omit the case of discounting on selling price. But in real world, it exists and is quite flexible in nature. On the other hand, in order to motivate customers to order more quantities for instant deterioration model usually supplier offers discount on selling prices. [1] developed an inventory model under continuous discount pricing. [7] 
studied an inventory problem under the condition that multiple discounts can be used to sell excess inventory. [17] and [20] mentioned that discount is considered temporarily for exponentially decaying inventory model. However, most of the studies except few, do not attempt to unify the two research streams: temporary price reductions and instant deterioration. This paper outlines the issue in details.

The paper tackles to investigate the effect of the approximation made by using the average payoff when determining the optimal values of the policy variables. The problem consists of the simultaneous comparison of crisp EOQ (CEOQ) and crisp entropic EOQ (CEnOQ) model, taking into account the conflicting payoffs of the different decision makers involved in the process. A policy iteration algorithm is designed with the help of [2] and optimum solution is obtained through LINGO software. In order to make the comparisons equitable a particular evaluation function based on discount is suggested. Numerical experiments are carried out to analyse the magnitude of the approximation error. The remainder of this paper is organised as follows. In section 2 assumptions and notations are provided for the development of the model. Section 3 describes the model formulation. In section 4, an illustrative numerical experiment is given to illustrate the procedure of solving the model. In addition, a comparative analysis between the profit maximization models is conducted. Section 5 presents the sensitivity analysis with critical discussion. Finally section 6 concludes this article with a brief summary and provides some suggestions for future research.

Table-1 Major Characteristics of Inventory Models on Selected Researches

\begin{tabular}{|c|c|c|c|c|c|c|c|}
\hline $\begin{array}{l}\text { Author(s) and } \\
\text { published Year }\end{array}$ & $\begin{array}{c}\text { Structure } \\
\text { of the } \\
\text { Model }\end{array}$ & Deterioration & $\begin{array}{c}\text { Inventory Model } \\
\text { Based on }\end{array}$ & $\begin{array}{l}\text { Type of } \\
\text { model }\end{array}$ & $\begin{array}{l}\text { Discount } \\
\text { allowed }\end{array}$ & Demand & $\begin{array}{c}\text { Back- } \\
\text { logging } \\
\text { allowed }\end{array}$ \\
\hline Mahata et al. (2006) & Fuzzy & Yes (constant) & EOQ & Cost & No & Constant & No \\
\hline Panda et al. (2009) & Crisp & $\begin{array}{c}\text { Yes } \\
\text { (Heavyside) }\end{array}$ & EOQ & Profit & Yes & $\begin{array}{c}\text { Stock } \\
\text { dependent }\end{array}$ & No \\
\hline Jaber et al. (2009) & Crisp & $\begin{array}{l}\text { Yes (on hand } \\
\text { inventory) }\end{array}$ & $\begin{array}{l}\text { EnOQ(Entropic } \\
\text { Order Quantity) }\end{array}$ & Profit & No & $\begin{array}{c}\text { Unit selling } \\
\text { price }\end{array}$ & No \\
\hline Tripathy et al. (2010) & Fuzzy & Yes (constant) & EnOQ & Profit & Yes & Constant & No \\
\hline Pattnaik (2010) & Crisp & Yes (constant) & EnOQ & Profit & Yes & Constant & No \\
\hline Tripathy (2008) & Fuzzy & $\begin{array}{c}\text { Yes } \\
\text { (Heavyside) }\end{array}$ & EnOQ & Profit & Yes & $\begin{array}{c}\text { Stock } \\
\text { dependent }\end{array}$ & No \\
\hline Skouri et al. (2007) & Crisp & Yes (Weibull) & EOQ & Cost & No & Ramp & $\begin{array}{c}\text { Yes } \\
\text { (partial) }\end{array}$ \\
\hline Present paper (2011) & Crisp & $\begin{array}{c}\text { Yes } \\
\text { (constant) }\end{array}$ & EOQ & Profit & Yes & Constant & No \\
\hline
\end{tabular}

\section{Notations and Assumptions}

\section{Notations}

$\mathrm{C}_{0} \quad$ : set up cost.

c : per unit purchase cost of the product.

$\mathrm{s} \quad$ : constant selling price of the product per unit $(\mathrm{s}>\mathrm{c})$.

h : : holding cost per unit per unit time. 
$\mathrm{r} \quad$ : discount offer per unit after deterioration.

$\mathrm{Q}_{1} \quad$ : order level for post deterioration discount on selling price with instant deterioration.

$\mathrm{T}_{1} \quad$ : cycle length for the above case.

\section{Assumptions}

1. Replenishment rate is infinite.

2. The deterioration rate $\theta$ is constant and $(0<\theta<1)$

3. Demand is constant and defined as follows.

a. $R(I(t))=a$

b. Where $a>0$ is the demand rate independent of stock level.

4. $r,(0 \leq r \leq 1)$ is the percentage discount offer on unit selling price during instant deterioration. $\alpha=(1-r)^{-n}(n \in R$, the set of real numbers) is the effect of discounting selling price on demand during deterioration. $\alpha$ is determined from priori knowledge of the seller with constant demand.

\section{Mathematical Model}

At the beginning of the replenishment cycle the inventory level raises to $Q_{1}$. As the time progresses it is decreased due to instantaneous stock with constant demand. Ultimately inventory reaches zero level at $T_{1}$. As instant deterioration starts from origin, $r \%$ discount on selling price is provided to enhance the demand of decreased quality items. This discount is continued for the rest of the replenishment cycle. Then the behaviour of inventory level is governed by the following system of linear differential equation.

$$
\frac{d I(t)}{d t}=-[\alpha a+\theta I(t)] \quad 0 \leq t \leq T_{1}
$$

with the initial boundary condition

$$
\left.\begin{array}{l}
I(0)=Q_{1} \\
\text { and } I\left(T_{1}\right)=0
\end{array}\right\} 0 \leq t \leq T_{1}
$$

Solving the equations,

$$
\begin{aligned}
& I(t)=\frac{a \alpha}{\theta}\left[e^{\theta\left(T_{1}-t\right)}-1\right] \quad 0 \leq t \leq T_{1} \\
& Q_{1}=\frac{a \alpha}{\theta}\left[e^{\theta T_{1}}-1\right]
\end{aligned}
$$

Holding cost of inventory in the cycle is,

$$
H C=h \int_{0}^{T_{1}} I(t) d t
$$

Purchase cost in the cycle is given by $P C=c Q_{1}$.

Total sales revenue in the order cycle can be found as 


$$
S R=S\left[\alpha(1-r) \int_{0}^{T_{1}} a d t\right]
$$

Thus total profit per unit time of the system is $\pi_{1}\left(r, T_{1}\right)$

$$
=\frac{1}{T_{1}}[S R-P C-H C-O C]
$$

On integration and simplification of the relevant costs, the total profit per unit time $\left(\pi_{1}\right)$ becomes

$$
\pi_{1}=\frac{1}{T_{1}}\left[s \alpha(1-r) a T_{1}-h\left[\frac{e^{\theta T_{1}}-1}{\theta}-T_{1}\right] \frac{a \alpha}{\theta}-c Q_{1}-C_{0}\right]
$$

If the product starts to deteriorate as soon as it is received in the stock, then there is only one option I may give post deterioration discount. The post deterioration discount on selling price is to be given in such a way that the discounted selling price is not less that the unit cost of the product, i.e. $s(1-r)-c>0$. Applying this constraint on unit total profit function I have the following maximization problem.

$$
\begin{array}{cl}
\text { Maximize } & \pi_{1}\left(r, T_{1}\right) \\
\text { Subject to } & r<1-\frac{c}{s} \\
& \forall r, T_{1} \geq 0
\end{array}
$$

The post-deterioration discount on selling price is to be given in such a way that the discounted selling price is not less that the unit cost of the product, i.e. $s(1-r)-c>0$.

The objective here is to determine the optimal values of $r$ and $T_{1}$ to maximize the unit profit function. It is very difficult to derive the results analytically. Thus some numerical methods must be applied to derive the optimal values of $r$ and $T_{1}$, hence the unit profit function. There are several methods to cope with constraint optimization problem numerically. But here the penalty function method [2] and LINGO software are implemented to derive the optimal values of the decision variables.

\section{Numerical Example}

The parameter values are $\mathrm{a}=80, \mathrm{~b}=0.3, \mathrm{~h}=0.6, \mathrm{~s}=10.0, \mathrm{C}_{0}=100.0, \mathrm{c}=4.0, \theta=0.03$ and $\mathrm{n}=2.0$.

After 178 iterations Table- 2 reveals the optimal replenishment policy for instant deterioration order quantity model with post deterioration discount. In Table 3 the numerical results of different CEOQ and CEnOQ models are illustrated separately. The behaviour of the total profit per unit time to the lot size and the cycle length of post deterioration discounted model is shown in Figure 1. 


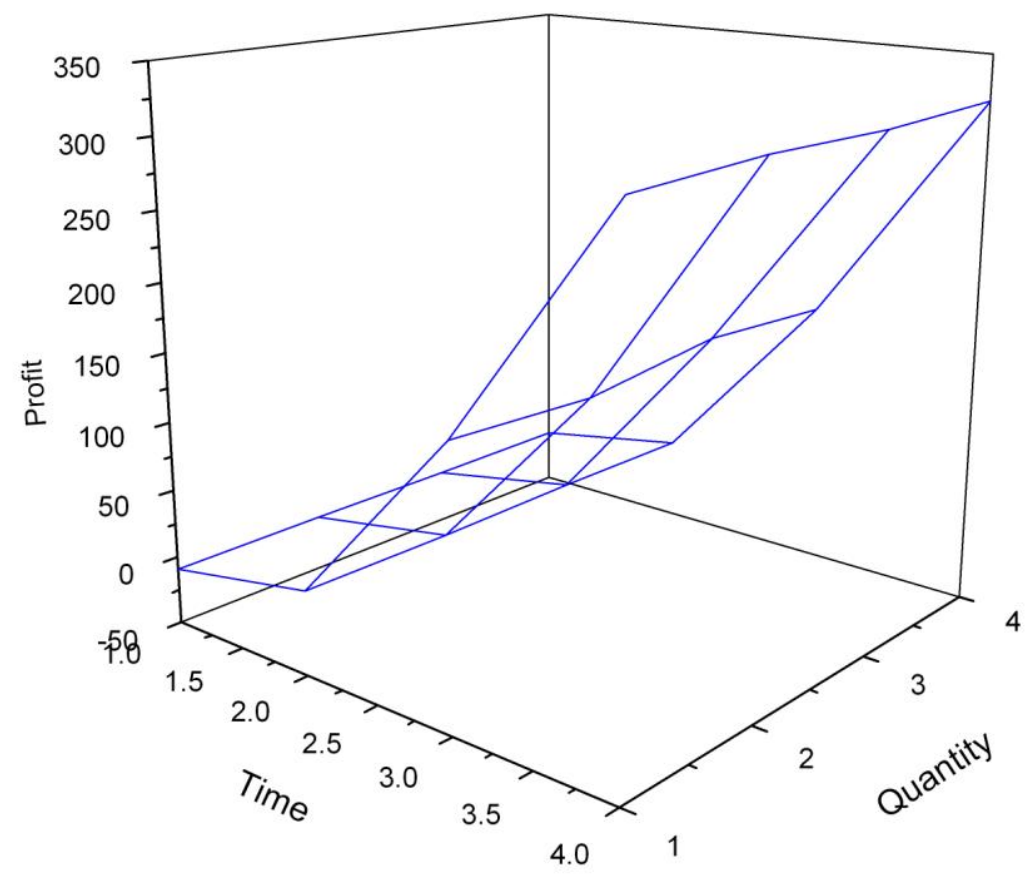

Figure1: The behaviour of the total profit to the lot size and the cycle length of post deterioration discounted model.

Table-2 The Numerical Results of the Instant Deterioration Crisp Economic Order Quantity (CEOQ) Model

\begin{tabular}{|l|c|c|c|c|c|c|}
\hline Model & $\begin{array}{c}\text { Local optimal } \\
\text { solution found } \\
\text { at iteration }\end{array}$ & $\mathrm{r}$ & $\mathrm{T}_{1}$ & $\mathrm{Q}_{1}$ & $\mathrm{EC}$ & $\pi_{1}$ \\
\hline $\begin{array}{l}\text { CEOQ (Only } \\
\text { post deterioration } \\
\text { discount) }\end{array}$ & 178 & 0.0766 & 1.6919 & 162.8242 & - & 374.0857 \\
\hline
\end{tabular}

Table-3 Comparison of Results for the different Post Deterioration Discount Models $(\mathrm{i}=1,2,3,4,5)$

\begin{tabular}{|l|c|c|c|c|c|c|}
\hline Model & $\begin{array}{c}\text { Local } \\
\text { optimal } \\
\text { solution } \\
\text { found at } \\
\text { iteration }\end{array}$ & $\mathrm{R}$ & $\mathrm{T}_{\mathrm{i}}$ & $\mathrm{Q}_{\mathrm{i}}$ & $\mathrm{EC}$ & $\pi_{i}$ \\
\hline CEOQ & 178 & 0.0766 & 1.6919 & 162.8242 & - & 374.0857 \\
\hline CEOQ [20] & 196 & 0.0708 & 1.6367 & 155.4112 & - & 369.3739 \\
\hline CEnOQ [12] & 141 & 0.0464 & 1.9176 & 173.6135 & 21.3170 & 362.0803 \\
\hline CEnOQ [16] & - & 0.4089 & 2.7502 & 636.1641 & - & 575.8885 \\
\hline CEnOQ [17] & 105 & 0.0392 & 1.8561 & 165.4009 & 21.1392 & 369.3739 \\
\hline
\end{tabular}


This paper investigates a computing schema for the EOQ in crisp sense. From Tables 3 it shows that the economic order quantity and entropic order quantity results are very approximate, i.e. it permits better use of EOQ as compared to entropic model. It indicates the consistency of the crisp EOQ model from the crisp EnOQ model. Table-4 provides the relative error of the optimum order quantity and the optimum total profit of the present model with the other different models.

Table-4 Relative Error (RE) of Post Deterioration Discount CEOQ Model with the different Models

\begin{tabular}{|c|c|c|}
\hline \multirow[t]{2}{*}{ CEOQ } & $\mathrm{Q}_{1}$ & 162.8242 \\
\hline & $\pi_{1}$ & 374.0857 \\
\hline \multirow[t]{2}{*}{ CEOQ } & $\mathrm{Q}_{2}$ & 155.4112 \\
\hline & $\pi_{2}$ & 369.3739 \\
\hline \multirow[t]{2}{*}{$\mathrm{RE}$} & $\%$ change & 4.5528 \\
\hline & $\%$ change & 1.2596 \\
\hline \multirow[t]{2}{*}{ CEnOQ } & $\mathrm{Q}_{3}$ & 173.6135 \\
\hline & $\pi_{3}$ & 362.0803 \\
\hline \multirow[t]{2}{*}{$\mathrm{RE}$} & $\%$ change & -6.6263 \\
\hline & $\%$ change & 3.2093 \\
\hline \multirow[t]{2}{*}{ CEnOQ } & $\mathrm{Q}_{4}$ & 636.1641 \\
\hline & $\pi_{4}$ & 575.8885 \\
\hline \multirow[t]{2}{*}{$\mathrm{RE}$} & $\%$ change & -290.7061 \\
\hline & $\%$ change & -53.9456 \\
\hline \multirow[t]{2}{*}{ CEnOQ } & $\mathrm{Q}_{5}$ & 165.4009 \\
\hline & $\pi_{5}$ & 369.3739 \\
\hline \multirow[t]{2}{*}{$\mathrm{RE}$} & $\%$ change & -1.5825 \\
\hline & $\%$ change & 1.2596 \\
\hline
\end{tabular}

\section{Sensitivity Analysis}

This paper has examined the sensitiveness of the decision variables, $r, T_{1}, Q_{1}$ and $\pi_{1}$ for each set of the parameters $\left(c, a, C_{0}\right)$ shown in Table- 5 . Table- 5 shows the relative changes of the price discount, $r$, the cycle length, $T_{1}$, and the total profit per unit time, $\pi_{1}$, when each of the parameters is being changed from +20 percent to +40 percent.

From Table-5, it can be seen that the optimum price discount, $r$, is less sensitive with respect to $c$ and highly sensitive with respect to the changes of the parameters a and $\mathrm{C}_{0}$. It also shows that the optimum order quantity, $\mathrm{Q}_{1}$ and the optimum cycle length, $\mathrm{T}_{1}$, are effectively sensitive with respect to the change of parameters $\mathrm{c}$, a and $\mathrm{C}_{0}$. On the other hand, it is observed that the optimal total profit per unit time, $\pi_{1}$, is highly sensitive with respect to the parameters $c$ and $a$; and is less sensitive for the change of the parameter $\mathrm{C}_{0}$. 
Table-5

Sensitivity Analysis of Instant Deterioration Discounted CEOQ Model

\begin{tabular}{|l|c|l|l|l|l|l|l|l|l|l|}
\hline Model & Parameter & $\begin{array}{l}\% \\
\text { Change }\end{array}$ & $\mathrm{R}$ & $\begin{array}{l}\% \\
\text { Change }\end{array}$ & $\mathrm{T}_{1}$ & $\begin{array}{l}\% \\
\text { Change }\end{array}$ & $\mathrm{Q}_{1}$ & $\begin{array}{l}\% \\
\text { Change }\end{array}$ & $\pi_{1}$ & $\begin{array}{l}\% \\
\text { Change }\end{array}$ \\
\hline \multirow{4}{*}{ CEOQ } & $\mathrm{c}$ & +20 & 0.81 & -2214.3 & 0.364 & 80.023 & 879.79 & -446.9 & 1918.733 & -441.8 \\
\cline { 2 - 11 } & \multirow{2}{*}{$\mathrm{a}$} & +40 & 0.63 & -1700.0 & 0.714 & 60.814 & 430.70 & -167.7 & 952.4172 & -168.9 \\
\cline { 2 - 11 } & \multirow{2}{*}{$\mathrm{C}_{0}$} & +20 & 0.00 & 100.00 & 4.003 & -119.7 & 68.042 & 57.706 & 47.05498 & 86.712 \\
\cline { 3 - 11 } & & +40 & 0.00 & 100.00 & 2.863 & -57.12 & 95.660 & 40.539 & 123.2117 & 65.208 \\
\cline { 3 - 10 } & & +40 & 0.15 & -328.57 & 0.704 & 61.363 & 78.058 & 51.481 & 441.8812 & -24.78 \\
\hline
\end{tabular}

\section{Critical Discussion}

The mathematical model is developed allowing post deterioration discount on unit selling price in crisp space. The numerical example is presented to justify the claim of model analysis. Temporary price discount for perishable products to enhance inventory depletion rate for profit maximization is an area of interesting research. This paper compares with EnOQ models which introduce the concept of entropy cost to account for hidden cost such as the additional managerial cost that is needed to control the improvement of the process.

Though lower amount of percentage discount on unit selling price in the form of post deterioration discount for larger time results in lower per unit sales revenue, still it is more profitable. Because the inventory depletion rate is much higher than for discount with enhanced demand resulting in lower amount inventory holding cost and deteriorated items. Thus it can be conjectured that it is always profitable to apply post deterioration discount on unit selling price to earn more profit. Thus the firm in this case can order more to get earn more profit.

These models can be considered in a situation in which the discount can be adjusted and number of price changes can be controlled. Extension of the proposed model to unequal time price changes and other applications will be a focus of the future work.

\section{Conclusion}

This paper provides a non linear profit maximization policy to extend arithmetic approach for perishable items with instant deterioration for the discounted entropic order quantity model in the adequacy domain. To compute the optimal values of the policy parameters a simple and quite efficient policy model was designed. Finally, in numerical experiments the solution from the instant deteriorated model evaluated and compared to the solutions of other different traditional CEnOQ policies. 
However, this paper shows few performance differences among a set of different inventory policies in the existing literature. Although there are minor variations that do not appear significant in practical terms, at least when solving the single level, incapacitated version of the lot sizing problem. From the analysis it is demonstrated that the retailer's profit is highly influenced by offering post discount on selling price. The results of this study give managerial insights to decision maker developing an optimal replenishment decision for instant deteriorating product. Compensation mechanism should also be included to induce collaboration between retailer and dealer in a meaningful supply chain. This paper is concluded by summarizing some of the managerial insights resulting from the work.

In general, for normal parameter values the relative payoff differences seem to be fairly small. The optimal solution of the suggested post deterioration discounted model has a higher total payoff as compared with EnOQ models. Conventional wisdom suggests that workflow collaboration in an entropic model in a varying deteriorating product in market place are promising mechanism and achieving a cost effective replenishment policy. Theoretically such extensions would require analytical paradigms that are considerably different from the one discussed in this paper, as well as additional assumptions to maintain tractability.

The approach proposed in the paper based on EOQ model seems to be a pragmatic way to approximate the optimum payoff of the unknown group of parameters in inventory management problems. The assumptions underlying the approach are not strong and the information obtained seems worthwhile. Investigating optimal policies when demand are generated by other process and designing models that allow for several orders outstanding at a time, would also be challenging tasks for further developments. Its use may restrict the model's applicability in the real world. Future direction may be aimed at considering more general deterioration rate or demand rate. Uses of other demand side revenue boosting variables such as promotional efforts are potential areas of future research. There are numerous ways in which one could consider extending our model to encompass a wider variety of operating environments. The proposed paper reveals itself as a pragmatic alternative to other approaches based on constant demand function with very sound theoretical underpinnings but with few possibilities of actually being put into practice. The results indicate that this can become a good model and can be replicated by researchers in neighbourhood of its possible extensions. In order to overcome most of the pitfalls in the existing inventory policy, further studies need to be carried out such as by introducing the concept of shortage and partial backlogging applying on it. The research of finding the best inventory policy with valid, rationale and robust characters is still an unending story. 


\section{References}

[1] Dave D. S., Fitzapatrick K. E., Baker J. R., “An advertising inclusive production lot size model under continuous discount pricing". Computational Industrial Engineering, 30:147-159, 1995.

[2] Deb K. "Optimization for engineering design". Prentice-Hall of India. New Delhi,2000.

[3] Ghare P. M., Schrader G. F., "A model for an exponentially decaying inventory". Journal of Industrial Engineering, 14:238-243, 1963.

[4] Goswami A., Choudhury K. S., "An EOQ model for deteriorating items with linear time dependent demand rate and shortages under inflation and time discounting". Journal of Operational Research Society, 46(6):771, 1995.

[5] Goyal S. K., Giri B. C., "Recent trends in modelling of deteriorating inventory". European Journal of Operations Research, (134):1-16, 2001.

[6] Jaber M. Y., Bonney M., Rosen M. A., Moualek I., "Entropic order quantity (EnOQ) model for deteriorating items". Applied mathematical modelling, 33(1):564578,2009 .

[7] Khouja M., "Optimal ordering, discounting and pricing in the single period problem". International Journal of Production Economics, 65:201-216, 2000.

[8] Liu L., Shi D., "An (s.S) model for inventory with exponential lifetimes and renewal demands". Naval Research Logistics, 46: 3956, 1999.

[9] Mahata G. C., Goswami A., "Production lot size model with fuzzy production rate and fuzzy demand rate for deteriorating item under permissible delay in payments". Journal of Operational Research Society of India, (43):359-375, 2006.

[10] Pal S., Goswami K., Chaudhuri K. S., "A deterministic inventory model for deteriorating items with stock dependent demand rate". Journal of Production Economics, 32:291-299, 1993.

[11] Panda S., Saha S., Basu M., "An EOQ model for perishable products with discounted selling price and stock dependent demand". CEJOR, (17): 31-53, 2009.

[12] Pattnaik M., "An entropic order quantity model (EnOQ) under instant deterioration of perishable items with price discounts". International Mathematical Forum, 5:2581-2590, 2010.

[13] Raafat E., "Survey of Literature on continuously deteriorating inventory model". Journal of Operational Research Society, UK, 42: 27-37, 1991.

[14] Shah N. H., Shah Y. K., "An EOQ model for exponentially decaying inventory under temporary price discounts". cahiers du CERO 35: 227-232, 1993.

[15] Silver E. A., Peterson R., "Decision system for inventory management and production Planning". 2nd edition, Willey, NewYork, 1985.

[16] Skouri K., Konstantaras I., Papachristos S., Ganas I., "Inventory models with ramp type demand rate, partial backlogging and weibull deterioration rate". European Journal of Operational Research, 2007. 
[17] Tripathy P. K., Pattnaik M., "An fuzzy arithmetic approach for perishable items in discounted entropic order quantity model". International Journal of Scientific and Statistical Computing, 1,(2):7-19, 2011.

[18] Tripathy P.K., Pattnaik M., "An entropic order quantity model with fuzzy holding cost and fuzzy disposal cost for perishable items under two component demand and discounted selling price". Pakistan Journal of Statistics and Operations Research, 4,(2):93-110,2008.

[19] Urban T. L., "Inventory model with inventory level dependent demand a comprehensive review and unifying theory". European Journal of Operational Research, 162: 792-804, 2005.

[20] Vujosevic M., Petrovic D., Petrovic R., "EOQ formula when inventory cost is fuzzy". International Journal of Production Economics, (45):499-504, 1996.

[21] Weatherford L. R., Bodily S. E., "A taxonomy and research Overview of Perishable asset revenue management: yield management, overbooking, and pricing". Operations Research, 40:831-844, 1992.

[22] Wee H. M., Law S. T., "Replenishment and pricing policy for deteriorating items taking into account the time value of money". International Journal of Production Economics, 71:213-220, 2001. 